REVISTA DE DERECHO UNED, NÚM. 21, 2017

\title{
ACERCA DE LA DEMOCRACIA DELIBERATIVA Y LA IMPORTANCIA DEL PROCESO EDUCATIVO EN SUS POSTULADOS
}

\author{
OF DELIBERATIVE DEMOCRACY THEORY \\ AND THE IMPORTANCE OF THE EDUCATIONAL PROCESS \\ IN ITS POSTULATES
}

GonZalo Gabriel CARRANZA

Resumen: Muchas son las teorías que tratan de dar una explicación acerca de la democracia. En este trabajo realizaremos un análisis de la evolución de las ideas desde el liberalismo hasta el participacionismo, para estudiar una vertiente llamada democracia deliberativa. Entendiendo sus postulados, veremos la importancia que tiene la educación y el sistema educativo para que pueda concretarse en la realidad, aunque también analizaremos sus principales debilidades y problemas de implementación en una sociedad masificada y globalizada.

Palabras clave: Democracia - Participación - Liberalismo - Democracia Deliberativa - Educación.

Abstract: There are many theories that attempt to shed light on what democracy is. In this paper, we will analise the evolution of those ideas from the liberalism and the participationism perspectives in order to embark upon the study of the so-called deliberative democracy dimension. Through understanding these postulates, not only will we come to see the importance of the roles that education and the educative system play in order to implement these ideas in reality, but also understand the main weaknesses and drawbacks of implementing them in an overcrowded and globalised society. 
Key Words: Democracy Participation - Liberalism - Deliberative Democracy - Education

Recepción original: 19/05/2017

Aceptación original: 27/10/2017

Sumario: Introducción. I. La democracia deliberativa. A. Algunas cuestiones previas a su estudio. B. Sobre los orígenes. B.1. La democracia elitista y los totalitarismos. B.2. El rechazo genera nuevas teorías: el participacionismo. B.3. El enclave superador de la dialéctica «elitistas vs. participacionistas»: los teóricos de la democracia deliberativa. C. Sobre sus principales postulados. C.1. El entorno superador a la democracia liberal. C.2. El compromiso con el bien común. C.3. El consentimiento ciudadano. C.4. La justificación de los pareceres y el proceso colaborativo. C.5. El empleo de la deliberación. C.6. El valor del factor emocional. D. Las condiciones para la puesta en práctica de la democracia deliberativa. II. La educación en la democracia deliberativa. A. Un papel destacado. B. Aquello para lo que se educa. C. Los programas de entrenamiento.III. Algunos puntos débiles de la teoría de la democracia deliberativa. A. No todo lo que brilla es oro. Conclusiones.

\section{INTRODUCCIÓN}

A lo largo de las últimas décadas, han resurgido los debates sobre la democracia en la teoría política contemporánea; quizás a modo de querer realizar un revisionismo de los mismos, de querer impulsar reformas o de propulsar nuevos modelos que lleven a sacudir el territorio donde anteriores teorías se encontraban. Todas ellas se han propuesto, al menos, pensar sobre distintos modelos de democracia.

No debemos dejar de observar que la mayoría de los ciudadanos que habitan el planeta viven en democracias, por lo que las variantes de hecho son numerosas, ya que los actores que forman parte de la vida democrática de los Estados demuestran asimilaciones distintivas según dónde se encuentren.

En las próximas líneas trataremos de analizar el discurso que subyace tras la teoría de la democracia deliberativa, bregando por dar un panorama general de la misma a lo largo de la historia, los autores y sus principales ideas, aciertos y posibles desaciertos. Asimismo, trataremos de analizar algunos aspectos esencialmente destacables en relación a la cuestión educativa de la teoría en cuestión, con el objetivo de vislumbrar si existe relación alguna entre el proceso educativo y la puesta en práctica de estas ideas. 


\section{LA DEMOCRACIA DELIBERATIVA}

\section{A. Algunas cuestiones previas a su estudio}

La sociedad contemporánea ha visto desarrollar en sus años de historia una larga lista de hechos que han modificado los escenarios del pensamiento de los autores. Esto se debe a que nadie queda exento de vivir en un espacio donde lo político, lo económico y lo social terminan -quiérase o no- afectando el desarrollo de las personas.

Desde la caída de los absolutismos monárquicos, la Revolución Francesa, los independentismos de las tierras de América, el comunismo, capitalismo, la caída del muro de Berlín, el derrumbamiento de las Torres Gemelas, las guerras de Irak, entre otros procesos, podríamos decir que la sociedad ha vivido el surgimiento, desarrollo y caída de distintos «ismos ${ }^{1}$, de ideologías, de pensamientos que siempre afectan a la sociedad.

El hecho de tener que vivir en distintos espacios donde el debate por la democracia reaparece luego de crisis parece destacable. Se ha podido apreciar quizás de forma latente en los últimos años, cuando aparecen en el escenario político personas cansadas del discurso imperante y que quieren un cambio, una renovación, bajo el grito del "que se vayan todos» ${ }^{2}$, tratando de tomar las riendas del asunto pero descubriendo -con mucho pesar- que en ciertas ocasiones no basta sólo con gritar al cielo, sino que hay que poner manos en el asunto.

Estos movimientos sociales han generado que los autores comiencen a replantearse los modelos de ciudadanías, de participación, de debate, de consensos, en fin: de democracia. Así, surgen ideas que hacen renacer el espacio de intercambios de conocimientos y que quieren enmarcar los procesos que, como hemos visto, se han ido desencadenando en las últimas décadas.

${ }^{1}$ Sobre ello, destaco la película Canadiense "Les Invasions Barbares» de Denys Arcand (que, por cierto, obtuvo distintos premios y nominaciones incluso de la Academia), donde los personajes discuten una noche acerca de lo que habían visto pasar durante décadas de vivencias juntos, llegando a la conclusión de que ellos mismos habían pasado por diversas «istas»: separatistas, independentistas, soberanistas, asociacionistas, existencialistas, anticolonialistas, marxistas, etc. En parte de su relato se preguntan: "¿existe algún 'ismo' que no hayamos adorado?». Recomiendo ver el vídeo de esa parte del film, disponible en https:/www.youtube.com/watch?v=50f2NfTpJhI.

${ }^{2}$ Sobre esto, se pueden analizar los procesos llevados a cabo en Argentina luego de la crisis del año 2001, o el proceso Español en medio de la crisis económica reciente y el famoso movimiento «15-M», como así también los movimientos dados en Brasil o Chile fruto de estudiantes movilizados queriendo cambiar la política imperante en materia educativa. 
Sobre esto, podemos también tener en cuenta el gran influjo que generó la aparición de medios masivos de comunicación y -en especial- internet y los móviles con datos, que permiten formas de expresión de la ciudadanía que ya son nuevas formas de hacer democracia. Hugo Aznar ha resumido estas cuestiones diciendo que "resulta evidente que estamos viviendo en los últimos años un incremento de las movilizaciones sociales. Muchas han estado provocadas por las consecuencias derivadas de la crisis económica que se inició en 2007. Sin embargo, es posible -y así parecen expresarlo las demandas de bastantes de estos colectivos- que respondan también a un descontento más profundo y a una demanda de reformas más amplias que las laborales y económicas» ${ }^{3}$.

Señala el autor, además, que han existido cambios antropológicos, psicosociales y sociopolíticos que han transformado a la ciudadanía y que son dignos de ser estudiados por los teóricos.

A todo lo expresado, debemos agregar el proceso de la globalización, donde «las turbulencias nacidas de la aceleración de los fenómenos de globalización han acrecentado la presión y la tensión reflexiva sobre cómo 'entender' la dinámica de unas sociedades cada vez más complejas y desde qué premisas abordar las nuevas funciones de la sociedad y la ciudadanía en una esfera pública multidimensional» ${ }^{4}$.

\section{B. Sobre los orígenes}

Entendiendo que el proceso que circunda al surgimiento de esta teoría tiene raíces de profunda conexión con la sociedad, es dable comenzar a entender los orígenes sobre los que subyace el entramado teórico previo.

\section{B.1. La democracia elitista y los totalitarismos}

Las sociedades posteriores a las grandes revoluciones que dieron lugar al surgimiento de los primeros movimientos constitucionales, había entendido la necesidad de la representación, de que, si bien la

${ }^{3}$ Cfr. AzNAR, Hugo. (2014). De masas a públicos: ¿cambios hacia una democracia deliberativa? En AznAR, Hugo y otros, De la Democracia de masas a la democracia deliberativa, Barcelona: Ariel, pág. 97

${ }^{4}$ Cfr. Menéndez Alzamora, Manuel. (2014). Repensar la democracia: los retos de una ciudadanía cosmopolita. En AzNAR, Hugo y otros, De la Democracia de masas a la democracia deliberativa, Barcelona: Ariel, pág. 127 
soberanía es popular, la mejor forma de progresar era dejando los asuntos públicos en unos pocos que tuvieran la capacidad de conducir los designios de los Estados. Junto a esto, cabe destacar que las primeras constituciones liberales demostraban también un reparto de derechos en los cuales la igualdad no era una de las banderas que se levantaba hasta el límite del mástil, sino que quedaba a media asta, ya que no todos tenían la capacidad de conducir y, mucho menos, de elegir.

Nos encontrábamos, pues, en un modelo de democracia que era ciertamente elitista, que no respondía quizás a los parámetros de la teoría política clásica. Como señala Pedro Jesús Pérez Zafrilla: «el elemento característico de la teoría elitista de la democracia es una concepción claramente pesimista de una amplia participación política» ${ }^{5}$. Estos elitistas «conciben al individuo desde la perspectiva del homo economicus; esto es, concernido unicamente por sus intereses privados y la protección de sus derechos individuales, de tal forma que sólo participa en política en tanto en cuanto ello le sea rentable para sus intereses privados» ${ }^{6}$.

Todo el pensamiento elitista llevaba consigo dos premisas grandes: los ciudadanos no tienen interés en lo público ${ }^{7}$ y carecen de capacidad para la toma de decisiones ${ }^{8}$.

Señalaba al respecto Carlos Santiago Nino que «la visión comúnmente llamada 'elitista' presupone, en forma similar a los utilitaristas, que los intereses de la gente o sus preferencias deberían ser tomados como dados en el proceso político. Los elitistas están resignados frente al hecho de que las preferencias de la gente tienden a ser autointeresadas y no creen que el sistema político debería estar diseñado para transformarlas» ${ }^{9}$.

El mismo autor expone las ideas de Joseph A. Schumpeter, quien logró con una crítica a las teorías clásicas de la democracia, construir una idea alternativa que se somete a esta visión elitista. Schumpeter sostiene así que la teoría clásica de la democracia «(...) prevaleció en

${ }^{5}$ Cfr. Pérez Zafrilla, Pedro Jesús. (2014). Génesis y estructura de la democracia deliberativa. En AzNAR, Hugo y otros, De la Democracia de masas a la democracia deliberativa. Barcelona: Ariel. pág. 139.

${ }^{6}$ Ídem. pág. 140.

${ }^{7}$ Sobre esto, recordar que el interés principal de los ciudadanos es la cuestión privada, por ello tendrían una distorsionada idea del bien común.

${ }^{8}$ Teniendo en cuenta que la toma de decisiones requeriría una importante especialización que no ostenta la mayoría de los ciudadanos.

${ }^{9}$ Cfr. Nino, Carlos S. (1997). La constitución de la democracia deliberativa. Barcelona: Gedisa. pág. 116. 
el siglo XVIII, que ve a la democracia como un método para generar decisiones politicas con el fin de materializar el bien común, permitiendo que la gente decida cuestiones a través de la elección del individuo que debería representar su voluntad» ${ }^{10}$.

Así, su propuesta superadora consistiría en una en la que «el método democrático es un sistema institucional que se utiliza para tomar decisiones politicas dentro del cual algunos individuos adquieren el poder para decidir luego de competir por el apoyo popular» ${ }^{11}$. Su apuesta es, de este modo, una apuesta a una casta elitista que puede tomar decisiones por el poder que posee, el que ha sido otorgado por el pueblo quien ha decidido quién debe conducirlos. Una de las cuestiones centrales que Nino reconoce como problema de este postulado es que "los partidos tienen el efecto de promover las cuestiones de políticas dominantes y la responsabilidad de los gobiernos hacia el electorado disminuye» ${ }^{12}$.

En este modelo liberal, los individuos están separados unos de otros, no existe una conexión entre ellos. No hay una forma de participación del ciudadano, el que queda al margen de la política y de la actividad pública, reservada a unos pocos. Aquí encontramos un discurso más privado que comunitario, una preocupación mayor por el «yo» que por el «nosotros». Hay una escisión total de la relación entre el representante y el representado que no genera vínculos más que en el voto y en el mantenimiento de una casta dirigencial elección tras elección.

A lo anteriormente enunciado, hay que agregarle el surgimiento de los totalitarismos a mitad del siglo XIX, que generaron una unidad de masas en los que se dificultaban los procesos de entendimiento del bien común, ya que existía de por sí una distorsión de ese elemento por parte de los dirigentes.

\section{B.2. El rechazo genera nuevas teorías: el participacionismo}

Frente a un pueblo oprimido y que tiene una cohesión social que impide el pensamiento autónomo, frente a un pueblo que tiene que ser mero espectador y no puede ayudar al mejoramiento de la sociedad a la que él mismo pertenece, surge en los autores un pensamiento

\footnotetext{
10 Ídem.

${ }^{11}$ Ídem. págs. 116-117.

12 Ídem. pág. 117.
} 
tendiente a entender la necesidad de romper las barreras existentes y que la ciudadanía de un paso hacia adelante.

Autores como Bachrach, Macpherson o Pateman impulsan en sus ideas el análisis de un proceso que era, ni más ni menos, superador del anterior modelo de ciudadanía. Macpherson, por ejemplo, estudia los movimientos estudiantiles de la década del 1960 que requerían mayor participación dentro de las Universidades ${ }^{13}$. Pateman, por su parte, desarrolló tareas de reasilimación teórica de autores clásicos como Rousseau, Mill o Tocqueville, no sólo en aras de entender a la participación, sino en el proceso educativo necesario para que la misma pueda desarrollarse con normalidad en las sociedades. Señala Pérez Zafrilla que "gracias a la participación, los individuos son formados por el sistema político en un sentido de razonabilidad y el compromiso con el todo social. Dejarán también de percibir una confrontación entre sus intereses propios y los de la sociedad, ya que estos se identificarán plenamente con el bien general» ${ }^{14}$.

Como vemos, el cambio se da en el ciudadano que ahora participa y que es educado en el proceso participativo. Los "participacionistas» -como se llamó a estos y otros autores críticos de la teoría elitistamarcan el corte con el elitismo y denuncian que estas ideas habían hecho que los ciudadanos pierdan confianza en el sistema político.

Pérez Zafrilla, rescatando algunas de las ideas centrales de Bachrach, dirá que "para devolver la confianza a los ciudadanos en la política se requiere impulsar nuevas formas de participación en la sociedad. La participación en los diversos ámbitos sociales sobre las decisiones que les afecten educará a los ciudadanos en el sentido de la responsabilidad que lo autores elitistas creían inexistente en los individuos corrientes» ${ }^{15}$.

El modelo participacionista está centrado en la idea del «nosotros» más que en la del «yo». Se piensa en clave ciudadana, con el marcado centro del beneficio del interés general a más del particular, con la mirada puesta en resolver los conflictos a más que promover barreras entre el pueblo. Aquí las personas comienzan a actuar, a ser

${ }^{13}$ Cabe destacar sobre esto que ya en los albores del Siglo XIX en Córdoba, Argentina, muchos estudiantes también habían levantado las banderas de la participación y llevaron a cabo la famosa Reforma Universitaria del '18 en la Universidad Nacional de Córdoba, movimiento que sería el puntapié inicial para diversos impulsos reformistas en América Latina.

${ }^{14}$ Cfr. Pérez Zafrilla, Pedro Jesús. (2014). Op. cit. pág. 143.

15 Ídem pág. 146. 
parte, a no quedar al margen, a pensar en clave comunitaria, a ser verdaderos ciudadanos que se comprometen.

Dentro del marco de estas ideas, hay algo en lo que quisiéramos llamar la atención: dichas teorías surgieron en la década de 1960 y en los últimos años -sobre todo desde 2001 en Argentina, por ejemplo, y luego en otros países como España con el famoso modelo del 15M en Plaza de Sol- han encontrado cabida nuevamente en los anclajes teóricos contemporáneos para señalar el papel que tienen que tener los ciudadanos frente a la política o, más bien, frente a los políticos. Así, mientras más participación exista, mayor será el compromiso ciudadano que se logre.

B.3. El enclave superador de la dialéctica «elitistas vs.

participacionistas»: los teóricos de la democracia deliberativa

Tomando como base los planteamientos que los participacionistas habían desarrollado, y en torno a una estructura superadora del modelo elitista y liberal de la política, surge una nueva corriente de pensamiento que busca dar la tecla en cuestiones que hacen a la deliberación que debe existir en toda democracia. Aquí, se toman los postulados del participacionismo, pero entendiendo que la mejor forma para llegar a la toma de decisiones dentro de ese modelo es a través de la deliberación, es decir, de los razonamientos hechos palabras que se utilizan para superar los conflictos existentes y encaminar los actos del pueblo hacia el bien común, su norte.

Joseph M. Bessette, en 1980, fue uno de los pioneros en usar el término "democracia deliberativa», en un trabajo "dedicado a la propuesta realizada por los federalistas Hamilton y Madison en el proceso constituyente de 1787» ${ }^{16}$. Allí sostiene una teoría acerca de que los autores del famoso "The Federalist» pensaban en establecer en los Estados Unidos de Norteamérica una democracia de este tipo.

Pérez Zafrilla habla de tres grandes corrientes de pensamiento de la democracia liberal, la que podríamos resumir de la siguiente forma:

- Una primera, republicana, que lleva consigo pensamientos de clásicos como Rousseu y que de la cual sería abanderado Benjamin Barber;

16 Ídem. pág. 149. 
- Una segunda, liberal, encabezada por Rawls, con sus teorías sobre el valor de la igual libertad como base de las relaciones políticas. Junto a él aparecen autores como Amy Gutman y Dennis Thompson, quienes se preocupan sobre los desacuerdos morales y sus implicancias en la toma de decisiones, junto a la ampliación del debate a todo el proceso político y a escuelas, medios de comunicación, etc. Señala Pérez Zafrilla dentro de esta corriente otros autores como Thomas Christiano, Joshua Cohen, David Crocker, entre otros; y

- Una tercera, sobre ética del discurso, donde el mayor exponente es Jürgen Habermas, postulante de que en el sistema democrático las decisiones políticas adoptadas, para ser legítimas, deben contar con la aceptación de todos los afectados por ellas. Sus ideas fueron seguidas po John Dryzek, James Bohman, Adela Cortina, entre otros.

Como bien indica el autor que venimos analizando, "el hecho de que la democracia deliberativa se haya desarrollado desde diversos ámbitos intelectuales, como el republicanismo, el liberalismo o la teoría crítica, entre otros, hará que, por un lado, las propuestas ofrecidas sean muy variadas, y por otro, que su oposición a esta democracia antagonista, que limita la participación política del ciudadano y favorece el papel de las elites, sea también diversa» ${ }^{17}$.

Como vemos, las distintas propuestas nos acercarán a distintos autores. A modo de ejemplo, una de las apuestas sobre esta teoría ha tenido el doctrinario argentino Carlos S. Nino, quien indica en primera persona que «la postura que defiendo es una postura dialógica. Mientras algunas visiones de este tipo conservan la separación entre política y moral, mi concepción visualiza estas dos esferas como interconectadas y ubica el valor de la democracia en la moralización de las preferencias de las personas. (...) El valor de la democracia reside en su naturaleza epistémica con respecto a la moralidad social» $^{18}$.

Nino dice de Rawls que "reconoce que la discusión entre una pluralidad de personas tiene efectos beneficiosos, pues de este modo se limita la parcialidad, se enriquecen las perspectivas, aumenta el conocimiento y se permite detectar errores en el razonamiento» ${ }^{19}$. Hará lo propio el autor, indicando algunas de las posturas de Jürgen Haber-

\footnotetext{
17 Ídem pág. 155.

${ }^{18}$ Cfr. Nino, Carlos S. (1997). Op cit. pág. 154.

${ }^{19}$ Ídem. pág. 157.
} 
mas, señalando que el filósofo alemán de Frankfurt sostiene que «el discurso práctico está constituido por interacciones comunicativas a través de las cuales los participantes coordinan sus comportamientos argumentando a favor o en contra de diferentes reclamos de validez con la finalidad de obtener un cierto consenso acerca de ellos. El principio que opera como puente no es un mero requerimiento gramatical o una demanda de consistencia sino que involucra una demanda de imparcialidad» ${ }^{20}$.

\section{Sobre sus principales postulados}

\section{C.1. El entorno superador a la democracia liberal}

Teniendo en cuenta que la democracia deliberativa surge con autores que "tratan de hacer frente desde sus planteamientos particulares al modelo democrático existente, el cual se encuentra inmerso en una grave crisis de confianza ante una ciudadanía apática y una clase politica poseedora de un poder omnímodo ${ }^{21}$, el marco de surgimiento de la teoría tiene que ver en mucho con el rechazo y la propuesta superadora, con un mirar hacia adelante, más que un mirar hacia atrás constantemente.

La democracia liberal imperante lleva consigo ideas que tienen que ver con lo siguiente:

- El fomento de que los ciudadanos decidan sus votos en las elecciones en función de intereses privados y no mirando al bien público;

- La existencia de luchas partidistas por la adhesión de votos y por conquistar el poder incluso con campañas que tiendan a eliminar a otros partidos, sin preocuparse por el bien común;

- El acaparamiento de los políticos de todas las acciones de la política, sin importar el rol de la ciudadanía, que queda enmascarada tras el voto.

Sobre la base de estos postulados es que surgirán las distintas ideas que trataremos de vislumbrar sobre la democracia deliberativa.

\footnotetext{
${ }^{20}$ Ídem. pág. 158.

${ }^{21}$ Cfr. Pérez Zafrilla, Pedro Jesús. (2014). Op. cit. pág. 154.
} 
C.2. El compromiso con el bien común

Una de las ideas centrales que tiene la democracia deliberativa es el necesario compromiso de los ciudadanos con el bien común. Así, se fomenta que los ciudadanos deban atender a las cuestiones de la ciudadanía saliendo de sí mismos y mirando hacia los demás $\mathrm{y}$, aunque parezca enredado, hacia ellos mismos, ya que todos forman parte de la noción de «bien común». Se parte de la concepción de una solidaridad social, más que de un egoísmo exacerbado. Las decisiones que se toman tienen una nota distintiva de racionalidad e imparcialidad, de ahí el hecho de que sean consideradas justas.

El gran problema que analizan los teóricos es el excesivo lugar que han tomado en los últimos años las luchas partidistas y la búsqueda de votos de quienes deberían representar al pueblo en la consecución del bien común, preocupándose más bien por sus intereses personales y por lograr hacer de la política un espacio de empleabilidad de unos pocos que se preocupan por sus intereses más que por los de la ciudadanía. Este problema se nota especialmente en los Parlamentos, donde existen grandes internas partidistas en cuestiones de votos, siguiendo criterios personales (o partidistas) y no en miras al bien común ${ }^{22}$. Ilustradoras son las palabras de Pérez Zafrilla, quien al respecto enuncia que «el sistema político actual se encuentra sometido a la lógica de la lucha de partidos, los cuales son ajenos a los verdaderos problemas de los ciudadanos ${ }^{23}$

Por todo lo mencionado, es clave la existencia y la necesidad de hablar del bien común como el norte hacia el cual tienden las decisiones personales y políticas. La participación del pueblo debe ser una condición indispensable para que exista una prevalencia de la democracia deliberativa.

\section{C.3. El consentimiento ciudadano}

Otra de las ideas esenciales de la democracia deliberativa es que los ciudadanos deben prestar su consentimiento para la toma de las

\footnotetext{
${ }^{22}$ Sobre esto, en miras a escenificar algunas de las ideas planteadas, recomiendo la serie "House of Cards», donde todo el rol que se manifiesta en los políticos es ni más ni menos que la lucha por el poder, no preocupándose por el bien común de los ciudadanos.

${ }^{23}$ Cfr. Pérez Zafrilla, Pedro Jesús. (2014). Op. cit. pág. 154.
} 
decisiones. Básicamente, por esto es que surge el tema de la deliberación para llegar a ese punto.

El consentimiento tiene que entenderse tanto en la expresión positiva como negativa, es decir, no podemos entender que todas las decisiones sean expresadas en forma positiva, ya que la expresión no afirmativa termina siendo, en fin, una expresión de aquello que ha consentido en negar la población.

Cuando uno consiente no sólo hace una expresión basada en los vocablos «si» $\mathrm{o}$ «no», sino que plantea a través del recurso de la lógica de los argumentos un parecer que se ha formulado en clave de conceptos concatenados que guardan coherencia, cohesión y que no tienen en sí apelación a recursos engañosos que dificulten la capacidad de adhesión o denegación popular a lo que se quiere referir. Así, no es dable el usar estrategias de la lógica para obtener un engaño a los demás, pues la esencia misma de lo que se plantea es que los ciudadanos puedan manifestar su parecer en miras al bien común y éste sería claramente atacado si se usan maniobras fraudulentas para obtener el beneplácito o no del pueblo.

En los procesos de democracia deliberativa importa que el sujeto sea el legítimo depositario de la decisión a partir de la expresión de su consentimiento, ya que no basta el recurso de extender la decisión a un tercero que la toma por él, sin ningún tipo de responsabilidad o imperio de información a los ciudadanos.

Así, los políticos que se preocupan por el bien común y asumen cargos de gobierno deben tener una expresión de sus decisiones ante el pueblo que se basen en recursos racionales que sean «aceptables para todos» ${ }^{24}$. Pérez Zafrilla indica que algunos autores como Habermas, Gutmann, Thompson o Bohman no defienden la participación directa del pueblo, sino que indican que la deliberación se debe entablar por procesos en medios de comunicación y parlamentos, en los que se lleve a cabo el ejercicio de la deliberación antes de que se tomen las decisiones, "de tal forma que pueda llegarse a una mejor decisión final» ${ }^{25}$.

Se busca, en fin, que la participación política se haga teniendo en cuenta que la democracia no es meramente delegativa, sino participativa y deliberante.

24 Ídem. pág. 156.

25 Ídem. 
C.4. La justificación de los pareceres y el proceso colaborativo

Una cuestión esencial dentro de la teoría de la democracia deliberativa es la manifestación de los pareceres de manera justificada. Esto implica un acto discursivo que pretenda inferir un planteamiento racional y lógico, justificado no sólo por cuestiones de reglas formales del discurso, sino también con cabida en cuestiones reales de la sociedad.

Nino señala que «bajo esta visión del proceso democrático como un sucedáneo de la práctica informal de la discusión moral, se requiere que todo participante, como sucede en esa práctica original, justifique sus propuestas frente a los demás. Si sus intereses son puestos sobre la mesa, ellos deben demostrar que son legítimos. Esta práctica presupone la existencia de una línea-delgada pero importante-que separa las posiciones que se adoptan en una discusión y que son reales y genuinas de aquellas que son falsas o que obviamente no cumplen con las reglas que subyacen a una discusión auténtica» ${ }^{26}$.

Esta justificación, basada en la deliberación que se lleva a cabo, permite que los actores del proceso deliberativo puedan detectar si existen errores fácticos y lógicos. Se vislumbra así en Nino, una construcción del discurso positiva y colaborativa, en la que los actores, al descubrir la inconsistencia del razonamiento de otro participante, no buscan el tirar abajo dicha construcción y someter a la vergüenza o el escándalo al mismo, sino que sea un espacio de lo que se llama vulgarmente «crítica constructiva». Así, las palabras del autor afirmarán nuestro parecer, señalando que «(...) es posible que los otros participantes en la discusión puedan detectar aquellas fallas y señalárselas de modo que el autor pueda corregirlas» ${ }^{27}$.

En esta cuestión de lógica en la cual entra en juego lo fáctico, el doctrinario argentino nos indicará desde su óptica que «específicamente, sostengo que la discusión con otros contribuye más a menudo a detectar errores fácticos y lógicos porque, en definitiva, la observancia fáctica y el uso de reglas de inferencia son el producto de facultades que todos tienen, y no es común que la mayoría de la gente cometa el mismo error. Incluso cuando la minoría está en lo correcto acerca de algunos hechos, la dinámica del conocimiento de la verdad tiende a ir de la minoría a la mayoría, y no en el sentido inverso» ${ }^{28}$.

\footnotetext{
${ }^{26}$ Cfr. Nino, Carlos S. (1997). Op. cit. pág. 171.

27 Ídem. pág. 174.

${ }^{28}$ Ídem. pág. 175.
} 


\section{C.5. El empleo de la deliberación}

Los autores sostendrán, asimismo, la necesidad de emplear la deliberación en el proceso político, tanto en la opinión pública como en el ámbito parlamentario. El uso de la deliberación permite a quienes tienen que tomar decisiones que las mismas sean pensadas, planificadas y consultadas en miras a la consecución del bien común. Lo que se busca es que no se recurra únicamente al recurso del voto secreto, sino que más bien se proceda a la toma de decisiones que respeten la participación y el uso de la palabra para defender las posturas y proceder a tomar decisiones racionales correctas, que disminuyan el riesgo que se tiene de que éstas atenten contra el bien común.

Algunas de las cuestiones que ayudan a que se tomen decisiones deliberativas, según Pérez Zafrilla, podrían ser:

- El incremento del conocimiento disponible, ya que cuando se delibera se tiene en cuenta la existencia de cuestiones que hacen tanto al beneplácito como el malestar ciudadano, es decir, los «pros y contras».

Muchas veces uno al sostener una postura se encasilla en ella y no escucha a las demás. La democracia deliberativa coadyuvaría a que se tomen decisiones sensatas, que tiendan a la consecución de soluciones más que problemas para la mayoría. Los autores sostienen que el uso del voto secreto y la no deliberación ayudan a la toma de medidas populistas que olvidan rasgos del bien común del pueblo;

- Permite la escucha y la expresión de intereses individuales, ya que cuando se delibera se permite que cada uno intercambie su opinión y la manifieste, pudiendo percibir de esta forma cuál es el verdadero bien común, aquello que resuena en toda la ciudadanía. Cuando un ciudadano escucha, se logra tomar conciencia de las distintas posturas existentes y

Esta toma de conciencia, entonces, los conduce a cambiar sus preferencias y evitar la autofrustración. Los altruistas, por ejemplo, podrían darse cuenta de que sus propios intereses chocan con otros y entonces cambiar sus elecciones para que los intereses de los demás puedan ser satisfechos ${ }^{29}$;

${ }^{29}$ Ídem. pág. 170. 
- Permite la detección de errores de información que tienen los individuos sobre el mundo y sobre sus propias preferencias, y esto se nota sobre todo cuando podemos indicar que el hombre empieza a comprender que en la sociedad hay un alter que también conforma su espacio vital, y que la decisión será para el conjunto, descubriendo muchas veces su equivocación al respecto de los problemas que afronta la sociedad y abriendo los ojos frente a ellos;

- Permite a los ciudadanos vencer los prejuicios que les llevan a favorecer sus propias concepciones e infravalorar la visión de otros, ayudando así a entender que no siempre la posición de uno es la correcta, sino que hay otros que pueden tener mejores argumentos que los suyos. He aquí la necesidad de que los recursos que se utilizan para la argumentación no sean falaces y permitan la comprensión racional correcta por parte de quienes escuchan las distintas posiciones al respecto;

- La deliberación dificulta la manipulación de la información que se produce en la opinión pública desde las elites políticas mediante los medios de comunicación afines, ya que cuanta más información existe, más complicado es manipular a la población. Aquí podríamos sostener que lo que se hace es velar por la inexistencia de monopolios de medios de comunicación, sino una participación abierta a distintos medios que puedan expresar así distintas posiciones al respecto, para que la ciudadanía comprenda las distintas facetas de los rasgos deliberativos existentes.

Si volvemos en el texto a los postulados Rawlsianos, podremos ver la clara influencia del pensamiento de este autor en la conformación de las ideas afirmativas en relación a la democracia deliberativa que asume el propio Pérez Zafrilla.

Ahora bien, no siempre ha existido un consenso en relación con la cuestión de la deliberación. Algunos autores se han hecho interrogantes acerca de la discusión que subyace en toda deliberación, como bien lo realizó James D. Fearon, cuando se preguntó: «¿Cuáles serían las razones válidas que un grupo de personas podrían tener para debatir determinados temas antes de tomar una decisión colectiva, en lugar de limitarse a votar o emplear alguna otra regla decisoria que no implique discusión? En otras palabras, ¿cuál es el sentido o el valor de discutir cosas antes que tomar decisiones políticas?» ${ }^{30}$.

${ }^{30}$ Cfr. Fearon, James D. (2001). La deliberación como discusión. En Elster, Jon y otros, La democracia deliberativa. Barcelona: Gedisa. 
Frente a su propio planteamiento, el autor discurre en seis razones o argumentos principales para discutir una cuestión antes de la toma de decisión ${ }^{31}$, los que ayudan a entender el valor de la deliberación.

\section{C.6. El valor del factor emocional}

Una de las cuestiones que fueron cuestionamientos internos de la teoría de la democracia deliberativa es si el factor emocional juega un papel que pone en jaque a las decisiones que se toman por vías racionales. Nos referimos, particularmente, a aquello que se ha denominado «psicología de las masas».

Carlos S. Nino se ha preocupado por esta cuestión, ya que «a menudo, el juicio de los individuos está bastante transformado por emociones incontroladas transmitidas de una persona a otra en un grupo de personas. Además, el carisma o la habilidad retórica de algunos, en comparación con la timidez o retraimiento de otros, puede hacer que incluso aquellos que adoptan posiciones imparciales tengan dudas acerca de quiénes poseen los argumentos más fuertes» ${ }^{32}$.

En relación a la cuestión emocional, hay que tener presente que no siempre dicha cuestión apela de forma negativa a la construcción de la deliberación, ya que en ocasiones es el instrumento que colabora con la defensa de argumentos sólidos con mayor ahínco.

Podríamos deducir de los postulados de Nino algunas afirmaciones que realiza en favor del apelo al factor emocional, como ser:

- Impulsan la discusión y permiten el movimiento en pos del convencimiento de los demás;

- Permite que los individuos asuman el rol de los demás, para que esa empatía denote el valor que tienen emocionalmente para ellos;

- Colabora con el proceso de sanciones sociales como el aislamiento y la asignación de culpa que recaerá sobre los que cometen errores evidentes o faltas en el proceso de argumentación.

Por lo mencionado, es importante atender a la cuestión de la emocionalidad de los actores que profesan los discursos, de manera tal que sea posible identificar si el apelo a dicha emocionalidad genera argumentaciones falaces o colabora con el proceso de la democracia deliberativa.

${ }^{31}$ Omitimos realizar referencia a los mismos en razón de la brevedad.

32 Cfr. Nino, Carlos S. (1997). Op. cit. pág. 175. 


\section{Las condiciones para la puesta en práctica de la democracia deliberativa}

Luego del análisis realizado precedentemente, es dable que analicemos algunas cuestiones que hacen a la democracia deliberativa y a sus condiciones para que pueda darse, realmente, esta teoría en la práctica.

De los postulados expuestos por Nino se pueden deducir algunas de las condiciones que serían necesarias para que se pueda poner realmente en práctica estas ideas, como ser ${ }^{33}$ :

- Que todas las partes interesadas participen en la discusión y decisión, así la cuestión a resolverse podría contar con el parecer de todos los involucrados en la misma. Vemos aquí que, además, es condición necesaria que su participación sea durante el proceso deliberativo y decisorio y no sólo en una de las etapas;

- Que participen de una base razonable de igualdad y sin ninguna coerción, de manera tal que la decisión que se tome no tenga diferenciaciones basadas a priori en ningún tipo ni que estén inducidas a la toma de posición por algún postulado que sancione o reprima la decisión que se quiera tomar;

- Que puedan expresar sus intereses y justificarlos con argumentos genuinos, esto entendiendo que la base de la racionalidad en la cual subyace la lógica argumentativa debe primar en cada uno de los juicios que se vislumbran desde los actores como condición indispensable para que la decisión sea la correcta;

- Que el grupo tenga una dimensión apropiada que maximice la probabilidad de un resultado correcto, de aquí que se requiere que no se lleve a cabo este proceso con grupos numerosos que dificulten la tarea de la toma de decisión. Como vimos, se puede pensar en una representación si y solo si, esta es responsable ante el pueblo y procede a dar publicidad e información previa al sometimiento de sus pareceres en los ámbitos deliberativos. Nino señala al respecto que "para algunos teóricos democráticos (...), la representación es una bendición. Esta no solo resuelve la imposibilidad de la comunicación directa y los detalles técnicos asociados al hecho de contar con comunidades políticas de grandes dimensiones, sino que también neutraliza el poder de las facciones ${ }^{34}$.

\footnotetext{
${ }^{33} \mathrm{Al}$ respecto, consultar el apartado "El alcance de la teoría» de Carlos Santiago Nino en la obra citada, págs. 180 y ss.

${ }^{34}$ Cfr. Nino, Carlos S. (1997). Op. cit. pág. 183.
} 
El mismo Nino indicará que para él la representación es «un mal necesario ${ }^{35}$, razonamiento al que llega porque considera que algunos representantes sólo tienen conocimiento de un sector determinado de la sociedad y existe la posibilidad de que anteponga sus propios intereses a los del bien común. Asimismo, considera que «la intermediación del representante puede ser inevitable, ya que a las personas directamente involucradas les puede faltar el tiempo, la experiencia y el poder para hacer que sus voces sean escuchadas" ${ }^{36}$;

- Que no haya una minoría aislada, pero que la composición de las mayorías y minorías cambie con las diferentes materias, de manera tal que todos tengan participación en el proceso y, según los distintos temas, se pueda apreciar diferencias en el grupo que favorezcan al intercambio de pareceres y a la conformación de una decisión que sea sostenida por el grupo en su conjunto.

En relación a la cuestión de la representación del grupo cuando existen minorías, autores como el argentino Roberto Gargarella se han preocupado por esbozar algunas ideas no sólo en relación a la existencia de un pluralismo de grupos dentro de la sociedad, sino también en indicar que deben existir canales para que las minorías puedan expresarse, cuestión que deja a cargo de las garantías institucionales por las que deben velar los tribunales supremos ${ }^{37} ; \mathrm{y}$

- Que los individuos no se encuentren sujetos a emociones extraordinarias, de manera tal que las decisiones no se tomen sólo por factores que subyacen al individualismo, sino en la racionalidad de la argumentación total.

Podríamos resumir todas estas cuestiones en cuatro fundamentos básicos para Nino, los que se resumen en «la participación libre e igual en el proceso de discusión y toma de decisiones; la orientación de la comunicación en el sentido de la justificación; la ausencia de minorías congeladas y aisladas, y la existencia de un marco emocional apropiado a la argumentación» ${ }^{38}$.

35 Ídem. pág. 184

36 Ídem. pág. 184.

${ }^{37}$ Sobre esto, se puede profundizar consultando Gargarella, Roberto (2001). Representación plena, deliberación e imparcialidad. En ElSTER, Jon. La democracia deliberativa, Barcelona: Gedisa.

${ }^{38}$ Cfr. Nino, Carlos S. Op. cit. pág. 192. 


\section{LA EDUCACIÓN EN LA DEMOCRACIA DELIBERATIVA}

\section{A. Un papel destacado}

Un papel principal dentro de la teoría de la democracia deliberativa lo asume la cuestión de la educación. En este punto debemos enfocarnos en vislumbrar cuál sería el papel que tiene que tener el proceso educativo en miras a la consecución de los postulados propios de la teoría y si es este punto de alguna manera un imperativo para su existencia.

Si partimos de la necesidad de la deliberación para la consecución de los ideales de esta teoría, tenemos que decir que uno de los puntos de esa partida debe recaer en el proceso educativo que se debe llevar a cabo. Así, la educación cumple un papel de notable trascendencia dentro de los teóricos de la democracia deliberativa, ya que es una cuestión que debe ser impulsada en miras a que el mismo proceso no caiga en sus imprecisiones y en aquellos defectos que se luchan por superar.

Si nos remontamos a la antigua Grecia, el mismo Aristóteles plantea la naturaleza del hombre como un ser social y político. En el ideal del «zoon politikon» que el mismo filósofo plantea, la consecución de las virtudes cívicas hará posible que el desarrollo de las polis conlleve a los hombres a ser mejores gracias su entorno. La cuestión de lo político quedará entablada no sólo como algo ideal, sino algo a lo que se debe tender en la realidad. La política, la participación, el entablar las relaciones dentro de la polis serán cuestiones en las cuales la educación tendrá un papel fundamental, ya que serán los mismos maestros los que guiarán por el recto sentido a los hombres. Es así que el hombre se desarrolla en su plenitud, sirviendo, colaborando con el bien común, con la política.

En este orden de ideas, Manuel Arias Maldonado ha señalado que «la política sería entonces la realización pública de la natural orientación humana a la cooperación con los demás, que mediante la debida educación permitiría a los individuos encontrar soluciones comunes a los problemas colectivos ${ }^{39}$. Vemos de esta forma que la cuestión de la educación es esencial para el encuentro de los fines a los que se propone la política en esta teoría, de manera tal que se pueda vislumbrar una democracia ordenada.

${ }^{39}$ Cfr. Arias Maldonado, Manuel (2007). La política en la teoría deliberativa. Notas sobre deliberación, decisión y conflicto. Revista Española de Ciencia Política, núm. 16, pág. 43. Disponible en: http://www.recp.es/index.php/recp/article/view/200/144

(C) UNED. Revista de Derecho UNED, núm. 21, 2017 
La educación en la teoría de la democracia deliberativa es un imperativo, ya que es la causa originante para que el sistema pueda encontrar frutos verdaderos y superadores a los procesos existentes.

Cuando en la familia y en las escuelas se piensa en clave de participación y deliberación, comienza un proceso en el cual se aprende a razonar «con» otros y no «de» otros. El ejercicio del discurso deliberativo supone aprender reglas de la lengua, de las expresiones, de la lógica interna que deben tener los argumentos que se quieren expresar y del carácter de justos que deben tener. Además, se hace hincapié en el hecho de la libertad de expresión, del establecimiento de reglas para poder comunicarse y de la necesidad de comunicar las ideas, en analogía con la publicidad que se debería dar de los actos de gobierno.

\section{B. Aquello para lo que se educa}

Este orden de ideas de la educación muestra el imperio del proceso de formación de las virtudes en los ciudadanos, es decir, de aquellos hábitos operativos buenos que le permiten desarrollarse en la sociedad. Estas virtudes de las que hablamos serían aquellas encaradas a fomentar el civismo, la participación, la consecución del bien común. Así, no sólo se denota la necesidad del estudio moral de las cuestiones que se indican, sino también el incipiente ejercicio dentro del aula o el espacio donde se imparten, de manera tal que se produzca la internalización de las mismas.

La educación para lograr una democracia deliberativa no sólo tiene que ser desarrollada en los marcos de las escuelas, ya que también se deberían inculcar estos valores en las mismas familias que forman a los niños y jóvenes y que los disponen para la consecución de los objetivos sociales en miras al bien común. De esta forma, comenzar por aquellas cuestiones que tienen que ver con las decisiones familiares podría ser un buen ejercicio para inculcar este tipo de valores.

Algunos podrían afirmar que el proceso educativo no tiene que ver con la puesta en práctica de la democracia deliberativa. Frente a esto, autores como Jon Elster, han planteado que «sería descabellado, por ejemplo, negar que la educación mejora la deliberación y también disparatado afirmar que todo el mundo podría estar bien educado» ${ }^{40}$. De esto se deriva, en consecuencia, la necesidad de afirmar que la educación

${ }^{40}$ Cfr. Elster, Jon (2001). La democracia deliberativa. Barcelona: Gedisa. pág. 28 
podría ser un motor que fomente y mejore la calidad de las deliberaciones que se llevan a cabo en las democracias.

La educación, asimismo, no sólo debería tender a comprender la vital importancia que tiene la participación ciudadana, sino también en fomentar el estudio de la lógica y la praxis en la argumentación dentro de las aulas, por ejemplo.

En los últimos años se ha vislumbrado a nivel global el cambio de nominación de las asignaturas que se enseñan en los institutos secundarios, con un notable cambio de los contenidos que tienen las mismas. Así, muchos sistemas educativos han optado por cambiar las materias relacionadas a la ética en la cual se enseñaban no sólo cuestiones relativas a tal disciplina -pero centradas en la imagen personal del sujeto-, sino también a la forma de organización del gobierno, por materias que hacen hincapié en la ética, ahora con una mirada pública y relacionista, con los límites que deben tener las actuaciones personales frente a la colectividad, y con la capacidad que tienen que tener los hombres de relacionarse. Además, se hace ahora foco en cuestiones de participación ciudadana, de necesidad del ejercicio de los derechos y de la posibilidad de hacer proyectos que fomenten la ejecución a pequeña escala de virtudes que tiendan al bien común, que hagan usar la palabra y el discurso, que sirvan a los alumnos para argumentar.

Así, materias como «formación ética y ciudadana» o "formación cívica» (entre otras diversas variantes de las denominaciones conforme a la nominación que han tenido en distintos espacios del globo), han cambiado su nombre y contenido por «ciudadanía y participación» o "educación para la ciudadanía», poniendo énfasis en el carácter participativo del sujeto que se está educando.

El objetivo central es, sin lugar a dudas, la concreción de sujetos que se preocupen por el bien común y que formen parte de la res pública, aunque sepamos que luego, al salir los jóvenes del colegio a las calles, podrán apreciar la clara dificultad que existe por la burocracia del sistema y por la subsistencia de algunos modelos de democracia representativa y delegativa, en los cuales la idea de abrir a nuevas propuestas, a dialogar, a escuchar, está netamente vedada.

\section{Los programas de entrenamiento}

James D. Fearon ha planteado que una de las cuestiones vitales para lograr un debate correcto podría ser el mejorar las cualidades

(C) UNED. Revista de Derecho UNED, núm. 21, 2017 
morales e intelectuales de los participantes en los mismos a través de diversos programas de entrenamiento. De esta forma, la deliberación misma se constituye en ese entrenamiento, el que debe ser fomentado desde la niñez para lograr mejores y más profundos procesos de razonamientos, que permitan de esta manera lograr decisiones que atiendan de manera ostensible la consecución del bien común.

Gracias a estos programas de entrenamiento, los hombres conseguirían el desarrollo de las virtudes humanas o cívicas. John Stuart Mill ha sostenido, por ejemplo, que los gobiernos deben ser órganos de la educación que promuevan el progreso mental de la comunidad, ya que ese será el caldo de cultivo de la mejora de los debates populares. Así, lo importante es que se fomente el proceso deliberativo en la educación, no solamente lo atinente a la toma de decisiones. Sobre esta cuestión, Fearon sostiene que "mantener discusiones en lugar de limitarse a hacer propuestas y votarlas daría como resultado el desarrollo de ciertas habilidades y quizá virtudes de los participantes. Se nos ocurren las siguientes posibilidades: elocuencia, habilidad retórica, empatía, cortesía, imaginación y capacidad de razonar» ${ }^{41}$.

Como vemos, son mayores los beneficios que las pérdidas de apostar por la educación en este sentido.

Si nos preguntamos cómo se podrían dar los procesos educativos en el sentido de la mayor participación y deliberación en las aulas, se podría decir que no sólo tiene que ver con la consecución de satisfacción de exámenes de tipo teóricos sobre virtudes o argumentación. Se requieren cuestiones netamente prácticas que conlleven a que a lo largo del proceso de educación de los sujetos se mantenga siempre levantado el estandarte de la democracia, desarrollando actividades que demuestren que en la práctica es posible tomar decisiones que denoten representaciones de diferentes facetas. Así, por ejemplo, debates en torno a cuestiones controvertidas en grupos áulicos o en la búsqueda del establecimiento de normas de convivencia podrían ser dinámicos para demostrar en los participantes la capacidad argumentativa basada en cuestiones racionales y fácticas, que tiendan al bien común de ese grupo de pares. De esta manera, se podría lograr un incipiente resultado positivo, como aquello que plantea Arias Maldonado: "un verdadero debate entre los ciudadanos, quienes en lugar de mostrar sus preferencias deben razonar sus puntos de vista desde una perspectiva pública» ${ }^{42}$.

${ }^{41}$ Cfr. Fearon, James D. (2001). Op. cit. pág. 83

${ }^{42}$ Cfr. Arias Maldonado, Manuel. Op. cit. pág. 45 


\section{ALGUNOS PUNTOS DÉBILES DE LA TEORÍA DE LA DEMOCRACIA DELIBERATIVA}

\section{A. No todo lo que brilla es oro}

Enunciamos este apartado con la frase popular «no todo lo que brilla es oro», ya que no siempre los postulados de la teoría de la democracia deliberativa mantiene una coherencia dentro de sus propios principios. Sobre esto, Manuel Arias Maldonado ha realizado una enumeración de algunas cuestiones que podrían considerarse como puntos débiles de la teoría ${ }^{43}$. A modo de parafraseo, trataremos de resumirlas bajo los siguientes argumentos:

- Si bien los teóricos de la democracia deliberativa piensan que unen a la sociedad, tenemos que destacar que también las distintas posiciones de los grupos pueden separarla, ya que la deliberación no sólo puede indicar convergencias, sino también diferencias que no se sustenten en argumentos racionales, sino en intereses en juego. Podría ser, así, que exista una tensión entre racionalidad discursiva y motivaciones subyacentes;

- No siempre los ciudadanos modificarán sus preferencias en relación a lo que otro plantea bajo el velo de la deliberación, ya que puede existir una negativa subjetiva basada, por ejemplo, en creencias religiosas, en posiciones políticas o en convicciones personales que van más allá de un buen argumento que haya sido esbozado lógicamente;

- Si nos basamos solamente en argumentos racionales, algunos que tengan mayor educación que otros podrán construir mejores argumentos y tendrán un predominio en el discurso que permitiría imponerse frente a los demás. El uso de la palabra y la construcción de razonamientos correctos lógicamente podrían esconder también alguna estrategia para modificación de la conducta de los demás;

- Muchas veces no se logra dar el lugar al proceso deliberativo a todos los espectros de la sociedad, más aún en sociedades tan cosmopolitas y con grupos diferenciados como la sociedad global en la que vivimos. De esta forma, no sería posible lograr la posibilidad de que todos los grupos expresen sus opiniones.

Como vemos, las críticas se basan en la contracara de los mismos argumentos de la deliberación. Así, consideramos que es también un

${ }^{43}$ Sobre esto, consultar ARIAS, Manuel. (2007). Op. cit. págs. 46-50 
ejercicio práctico de la propia democracia deliberativa la posibilidad de tenerlos en cuenta a la hora de tomar una decisión al respecto del parecer social.

Entendemos, además, que el modelo de democracia deliberativa es netamente complicado en sociedades globales como en las que vivimos, donde la masa del pueblo que se gobierna es tan amplia que es poco probable que se abra la posibilidad de atender a este tipo de modelos. Aún así, en ciertas comarcas, comunas, pequeños pueblos, este modelo puede encontrar cabida y ser un ejemplo a seguir por muchos. Aún así, como hemos visto, no es incompatible con un modelo de representación, aunque ésta puede caer en el pecado de convertirse en meramente delegativa si no se da correcta información al pueblo, si no se trata de proyectar en los espacios de dirigencia los postulados básicos sobre los que se asienta este modelo.

\section{CONCLUSIONES}

Las teorías no se quedan sólo en las palabras, sino que ayudan desde las mismas a modificar la realidad en la que viven los ciudadanos.

Cuando hablamos de la democracia deliberativa la asumimos como una alternativa a las diversas teorías existentes en relación al gobierno del pueblo para el pueblo, en la que se quiere contrarrestar cualquier recurso al elitismo, la tiranía o la oligarquía.

Vivimos en sociedades que tienden, día a día, a fomentar los procesos de tomas de decisiones democráticos, pero consideramos ciertamente complicado el poder someter a todas las sociedades a procesos de democracia deliberativa. Sumimos nuestro parecer en las propias flaquezas que tiene el sistema y en la concreta deficiencia que existe en muchas ocasiones en el proceso educativo que implica un germen en el cual el cultivo termina denotando decisiones populistas, irracionales y absolutamente delegativas. Asimismo, esas deficiencias son las que deben ser atacadas. Necesitamos espacios educativos en los que se inculquen virtudes humanas y cívicas y en los que esas virtudes puedan ser defendidas no sólo por convicciones personales -de las cuales se deben cuidar en no caer en fanatismos-, sino que puedan ser defendidas por razonamientos construidos mirando dos cuestiones esenciales: la consecución del bien común y el pensamiento lógico que tienda hacia una realidad mejor para todos y no para quien la expone o un grupo determinado de personas. 
Este ideal es difícil de construir en sociedades altamente diversificadas y separadas, pero quizás el intento por sembrar desde aulas o desde la misma familia la semilla del civismo permita, al menos, poder vivir en paz y sabiendo que en el otro también está el bien de todos.

\section{BIBLIOGRAFÍA}

Arias Maldonado, Manuel. La política en la teoría deliberativa. Notas sobre deliberación, decisión y conflicto. Revista Española de Ciencia Política, núm. 16, 2007, pág. 43.

AzNaR, Hugo. De masas a públicos: ¿cambios hacia una democracia deliberativa? En AznaR, Hugo y otros, De la Democracia de masas a la democracia deliberativa, Barcelona: Ariel. 2014.

FEARON, James D. La deliberación como discusión. En ElSTER, Jon y otros. La democracia deliberativa. Barcelona: Gedisa. 2001.

Franzé, Javier y otros. Democracia: ¿consenso o conflicto? Madrid: Catarata. 2014.

GARGARELLA, Roberto. Representación plena, deliberación e imparcialidad. En ElSTER, Jon y otros. La democracia deliberativa, Barcelona: Gedisa. 2001.

Gutmann, Amy y Thompson, Dennis. Democracy and disagreement. Cambridge: The Belknap Press of Harvard University Press. 1996.

Habermas, Jürgen. Facticidad y validez. Madrid: Trotta. 1998.

HERNÁNDEZ, Andrés y otros. Republicanismo contemporáneo. Igualdad, democracia deliberativa y ciudadanía. Bogotá: Siglo del Hombre.

Menéndez Alzamora, Manuel. (2014). Repensar la democracia: los retos de una ciudadanía cosmopolita. En AzNAR, Hugo y otros, De la Democracia de masas a la democracia deliberativa, Barcelona: Ariel. 2002.

Nino, Carlos S. La constitución de la democracia deliberativa. Barcelona: Gedisa. 1997.

Pérez Zafrilla, Pedro Jesús. Génesis y estructura de la democracia deliberativa. En AzNAR, Hugo y otros, De la Democracia de masas a la democracia deliberativa. Barcelona: Ariel. 2014. 
